\title{
Structured multiphase reactors based on fibrous catalysts: nitrite hydrogenation as a case study
}

\author{
V. Höller, I. Yuranov, L. Kiwi-Minsker, A. Renken* \\ Swiss Federal Institute of Technology, LGRC-EPFL, CH-1015 Lausanne, Switzerland
}

\begin{abstract}
A new reactor concept designed as a bubble column staged with fibrous catalytic layers is tested on pilot-scale for the reduction of nitrite to nitrogen by hydrogen. Carbon dioxide is used to neutralize the hydroxide ions produced during hydrogenation of nitrite. The effective reaction rate was found to depend on the superficial gas velocity $u_{\mathrm{g} 0}$. The fibrous catalysts demonstrated a high selectivity towards nitrogen. The influence of the mass transport on the effective kinetics is discussed and the volumetric liquid-solid mass transfer coefficient $k_{\mathrm{S}} a_{\mathrm{S}}$ is estimated as a function of the superficial gas velocity $u_{\mathrm{g} 0}$. The selectivity was found to be independent of the hydrodynamics. () 2001 Elsevier Science B.V. All rights reserved.
\end{abstract}

Keywords: Structured catalysts; Multistage bubble column; Nitrite reduction; Hydrodynamics; Fibrous materials/packing/fabrics

\section{Introduction}

The nitrite removal from ground water is becoming an environmental problem of major concern due to high toxicity of nitrites. Conventional physicochemical methods, like ion exchange, reverse osmosis and electrodialysis allow effective removal of nitrite ions after concentrating them, but do not generally achieve the problem of their complete disposal. The most environmentally benign methods are based on selective reduction of nitrite to nitrogen by micro-organisms or catalytically over noble metals [1-7]. The biological process is slow, complex and includes cost intensive post-treatment steps to remove by-products. The main problem of the catalytic reduction is the ammonia formation as a by-product and a strong $\mathrm{pH}$ dependence of the catalytic activity. In general, both activity and

\footnotetext{
* Corresponding author. Tel.: +41-21-693-3181; fax: +41-21-693-3190.

E-mail address: albert.renken@epfl.ch (A. Renken).
}

selectivity towards nitrogen decrease with increasing $\mathrm{pH}$ value. During the nitrite reduction by hydrogen, hydroxide ions are formed leading to a $\mathrm{pH}$ gradient along the catalyst pores and a $\mathrm{pH}$ change in the reactor. To neutralize the hydroxide ions Pintar et al. [7-9] proposed to supply a hydrogen/carbon dioxide mixture to the reactor. Depending on the ions present and the partial pressure of $\mathrm{CO}_{2}$, a $\mathrm{pH}$ in the range $4-5.5$ results.

$$
\begin{aligned}
\mathrm{CO}_{3}{ }^{2-}+\mathrm{CO}_{2}+\mathrm{H}_{2} \mathrm{O} \leftrightarrow 2 \mathrm{HCO}_{3}{ }^{-}, \\
2 \mathrm{OH}^{-}+\mathrm{CO}_{2} \leftrightarrow \mathrm{CO}_{3}{ }^{2-}+\mathrm{H}_{2} \mathrm{O}
\end{aligned}
$$

To avoid transport limitations within the pores, catalytic particles of small size were used $[2,3,7]$. In a technical application the minimal size of these particles is, however, limited by the filtration of catalyst powder from the water after the reaction. To overcome this problem, Hähnlein et al. [10] suggested incorporating the fine catalyst particles into hollow fibers of an inner diameter of $200 \mu \mathrm{m}$, whereas Daub et al. [11] proposed to use catalytic membranes for the reduction 


\begin{tabular}{|c|c|}
\hline \multicolumn{2}{|c|}{ Nomenclature } \\
\hline$a$ & specific surface area $\left(\mathrm{m}^{2} / \mathrm{m}^{3}\right)$ \\
\hline AGF & $\begin{array}{l}\text { D-type glass fiber covered } \\
\text { with } \gamma-\mathrm{Al}_{2} \mathrm{O}_{3}\end{array}$ \\
\hline$c$ & concentration $\left(\mathrm{mg}^{-1}\right)$ \\
\hline$D$ & diameter of a catalyst thread (m) \\
\hline$D_{\text {eff }}$ & effective diffusion coefficient $\left(\mathrm{m}^{2} / \mathrm{s}\right)$ \\
\hline DGF & D-type glass fiber \\
\hline ID & inner diameter of reactor (mm) \\
\hline$k_{\text {eff }}$ & effective reaction constant $\left(\mathrm{s}^{-1}\right)$ \\
\hline$k_{\mathrm{R}}$ & intrinsic reaction constant $\left(\mathrm{s}^{-1}\right)$ \\
\hline$k_{\mathrm{L}} a_{\mathrm{G}}$ & $\begin{array}{l}\text { volumetric gas-liquid mass transfer } \\
\text { coefficient }\left(\mathrm{s}^{-1}\right)\end{array}$ \\
\hline$k_{\mathrm{S}} a_{\mathrm{S}}$ & $\begin{array}{l}\text { volumetric liquid-solid mass transfer } \\
\text { coefficient }\left(\mathrm{s}^{-1}\right)\end{array}$ \\
\hline$K_{\mathrm{R}}^{\prime}$ & $\begin{array}{l}\text { intrinsic reaction } \\
\text { constant }\left(1 \mathrm{~min}^{-1} \mathrm{~g}_{\mathrm{pd}}{ }^{-1}\right)\end{array}$ \\
\hline$L$ & length $(\mathrm{mm})$ \\
\hline$P$ & dimensionless power supply $(-)$ \\
\hline$\Delta p_{\mathrm{f}}$ & $\begin{array}{l}\text { frictional pressure drop } \\
(\mathrm{kPa} / \text { fabric layer })\end{array}$ \\
\hline$Q$ & volume flow $\left(\mathrm{m}^{3} / \mathrm{s}\right)$ \\
\hline$S_{\text {cat }}$ & catalyst surface $\left(\mathrm{m}^{2}\right)$ \\
\hline$t$ & time $(s)$ \\
\hline$u_{\mathrm{g} 0}$ & superficial gas velocity $(\mathrm{cm} / \mathrm{s})$ \\
\hline$u_{10}$ & superficial liquid velocity $(\mathrm{cm} / \mathrm{s})$ \\
\hline$V_{\text {cat }}$ & catalyst volume $\left(\mathrm{m}^{3}\right)$ \\
\hline$X$ & nitrite conversion $(-)$ \\
\hline Y & Weisz modulus $(-)$ \\
\hline \multicolumn{2}{|c|}{ Subscripts } \\
\hline $\mathrm{NH}_{4}$ & ammonia \\
\hline $\mathrm{Pd}$ & palladium \\
\hline$S$ & catalyst surface conditions \\
\hline 0 & initial \\
\hline
\end{tabular}

of nitrate. Pintar and Batista [12] used porous egg shell catalysts with a diameter of $1.7 \mathrm{~mm}$ and a thickness of the reaction zone of $120 \mu \mathrm{m}$ in conventional fixed bed reactors and found a strong influence of the mass transport processes on the effective kinetics.

Recently, we studied the kinetics of the reduction of nitrite ions in water over Pd supported on structured fibrous materials [13]. The studies were concentrated on the investigation of the intrinsic kinetics of the catalytic nitrite reduction, since this process appears to be the limiting step in the reduction of nitrate to nitrogen [5]. In the present paper, a multistage-cascade bubble column, in which the trays are made from fibrous supported catalysts is suggested as reactor concept. This concept demonstrates several advantages for the catalytic denitrification [5], like a narrow residence time distribution and a redistribution of the gasand liquid-phases at each catalyst layer [14-16] thus avoiding the formation of dead zones or channeling.

The objective of the present work is to evaluate the use of a bubble column staged with composite ceramic fibers as supports for Pd catalysts in respect to their technical application in nitrite reduction. The overall reaction kinetics depend strongly on transfer processes like gas-liquid and the liquid bulk-solid surface mass transfer, therefore the influence of the hydrodynamics on the reactor performance and the selectivity towards nitrogen was studied in detail.

\section{Experimental}

\subsection{Catalyst preparation and characterization}

D-type glass fibers (DGF) in form of fabrics were used for the catalyst preparation as received. The fabrics were woven from threads with a diameter of $0.35 \mathrm{~mm}$ consisting of a bundle of filaments (diameter $\sim 7 \mathrm{~mm}$ ).

Composite ceramic-like fibrous supports (AGF) were prepared from DGF by treating them first in a boiling aqueous $\mathrm{HCl}$ solution (3.7\%) in order to create surface roughness. After rinsing the fabrics in distilled water, aluminum hydroxide was deposited via precipitation from $\mathrm{Al}\left(\mathrm{NO}_{3}\right)_{3}$ aqueous solution followed by calcination in air at $550^{\circ} \mathrm{C}$. This procedure results in the formation of a thin $\gamma$-alumina layer $(6 \mathrm{wt} . \%)$ on the glass filaments as confirmed by X-ray studies.

$\mathrm{Pd}$ as an active component was deposited on the AGF support via impregnation from aqueous solution of palladium(II) acetate (purum, Fluka Chemie AG, Buchs, Switzerland). The Pd loading was kept constant at $1 \mathrm{wt} . \%$ for all experiments. Before starting the reaction, the catalysts were reduced in a sodium formate (HCOONa) aqueous solution $(10 \mathrm{wt} . \%)$ at $80^{\circ} \mathrm{C}$. The $1 \% \mathrm{Pd} / \mathrm{AGF}$ catalyst obtained by this preparation method shows a high activity and a high selectivity towards nitrogen [13]. 


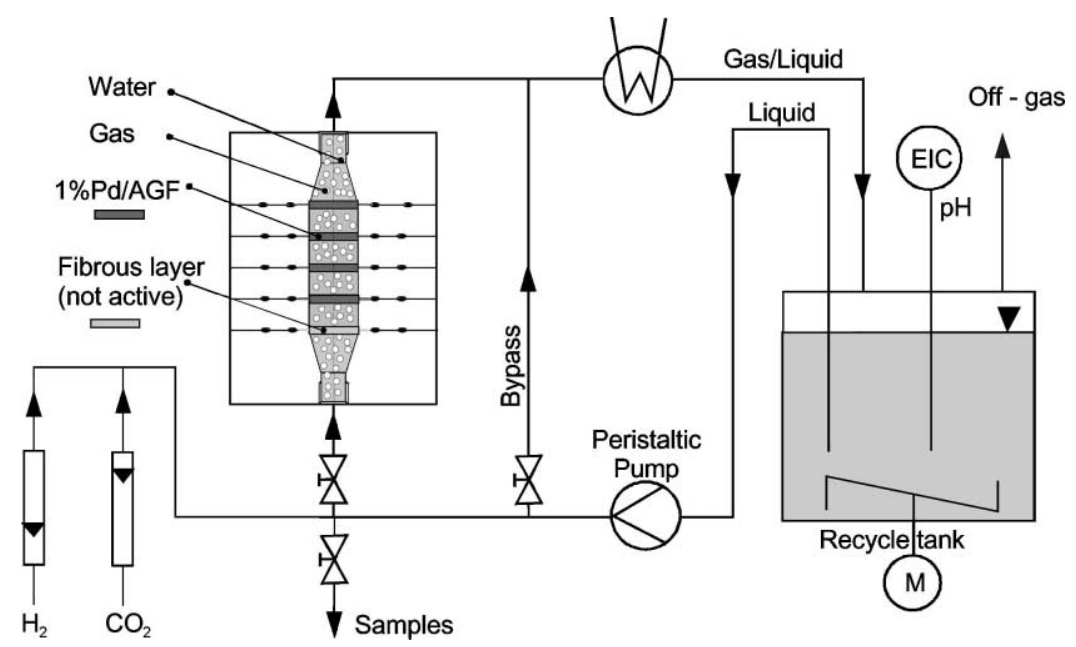

Fig. 1. Experimental set-up for the hydrogenation of nitrite with hydrogen in a bubble column loop reactor staged with $1 \% \mathrm{Pd} / \mathrm{AGF}$ catalysts.

\subsection{Experimental set-up and procedure}

An acrylic glass column with an inner diameter ID of $24 \mathrm{~mm}$ was used as a recycle reactor as presented in Fig. 1. The reactor was staged with five fibrous layers, with a distance of $15 \mathrm{~mm}$ between them. The first stage at the reactor bottom consisted of a non-active fibrous layer to guarantee a good gas-liquid distribution. In the following four stages the Pd alumina/silica catalyst ( $1 \% \mathrm{Pd} / \mathrm{AGF}$ ) with a total mass of $0.46 \mathrm{~g}$ was used as distributor plate. The gas- and liquid-phases were flowing co-currently upwards. Hydrogen and carbon dioxide flows were controlled by flow meters (Vögtlin, Switzerland). The superficial gas velocities $u_{\mathrm{g} 0}$ was varied between 0.9 and $24.5 \mathrm{~cm} / \mathrm{s}$ at a constant composition of $10 \% \mathrm{H}_{2}$ and $90 \% \mathrm{CO}_{2}$.

The recycle tank allowed the separation of gasand liquid-phases and monitoring the $\mathrm{pH}$ value by a Metrom-Stat-Titrino 718 equipped with an Aquatrode electrode.

For a typical experiment a liquid volume of $260 \mathrm{ml}$ was prepared from distilled water and sodium nitrite to give an initial nitrite concentration of approximately $10 \mathrm{mg} / \mathrm{l}$. Before starting the experiments, the solution was saturated with hydrogen/carbon dioxide by recycling the gas/liquid mixture through the by-pass. After $30 \mathrm{~min}$, the reaction was started by closing the by-pass-valve and simultaneously opening the valve before the reactor. The temperature was kept constant at $293 \mathrm{~K}$ by a heat exchanger. All experiments were performed under atmospheric pressure (1 bar). Samples were periodically taken and analyzed for nitrite and ammonia concentration via spectrometer Nova 60 (Merk). For determination of nitrite the Griess' reaction (absorbance maximum at $525 \mathrm{~nm}$ ) and for ammonia the Berthelots's reaction (absorbance max at $690 \mathrm{~nm}$ ) were used [17].

The influence of inner mass transport processes in the porous catalysts on the effective reaction rate was estimated from Weisz modulus $\Psi$ :

$$
\begin{aligned}
\Psi & =\left(\frac{V_{\text {cat }}}{S_{\text {cat }}}\right)^{2} \frac{m+1}{2} \frac{k_{\mathrm{eff}} c_{\mathrm{S}}^{m}}{D_{\mathrm{eff}} c_{\mathrm{S}}} \\
& =\left(\frac{D}{4}\right)^{2} \frac{m+1}{2} \frac{k_{\mathrm{eff}} c_{\mathrm{S}}^{m-1}}{D_{\mathrm{eff}}}
\end{aligned}
$$

where $V_{\text {cat }}$ is the catalyst volume, $S_{\text {cat }}$ the catalyst surface, $m$ the reaction order, $k_{\text {eff }}$ the effective reaction rate constant, $D_{\text {eff }}$ the effective diffusion coefficient and $c_{\mathrm{S}}$ the surface reactant-concentration at the catalyst outer surface. The relation between Weisz modulus $\Psi$ and the catalyst effectiveness factor $\eta$, which gives the ratio between the effective reaction rate and the reaction rate without inner diffusion limitations is given in text books of chemical reaction engineering [18].

The dimensionless power supply $P$ is calculated as a function of the frictional pressure drop $\Delta p_{\mathrm{f}}$ and the 
volumetric gas flow $Q$ :

$P=\frac{\left.\Delta p_{\mathrm{f}}\right|_{\mathrm{u}_{\mathrm{g}} 0} Q}{\left.\Delta p_{\mathrm{f}}\right|_{\mathrm{u}_{\mathrm{g} 0}, \max } Q_{\max }}=\frac{\left.\Delta p_{\mathrm{f}}\right|_{\mathrm{u}_{\mathrm{g} 0}} u_{\mathrm{g} 0}}{\left.\Delta p_{\mathrm{f}}\right|_{\mathrm{u}_{\mathrm{g} 0}, \max } u_{\mathrm{g} 0, \max }}$

As reference value the maximal superficial gas velocity $u_{\mathrm{g} 0, \max }=26.4 \mathrm{~cm} / \mathrm{s}$ is used.

\section{Results and discussions}

\subsection{Effective kinetics}

For some typical experiments, the nitrite and ammonia concentrations as a function of time are given in Fig. 2. In all experiments the nitrite depletion follows a first-order decay:

$$
\frac{c_{\text {Nitrite }}}{c_{\text {Nitrite }, 0}}=\exp \left(-k_{\text {eff }} t\right)
$$

The ammonia production increased approximately linearly with the reaction time. The formation of hydroxide ions during the nitrite reduction [3] leads to a linear increase of the $\mathrm{pH}$ value with the amount of converted nitrite ions, as presented in Fig. 3. The $\mathrm{pH}$ value rises approximately 0.35 units and remains at a low level of 4.5 due to the neutralization reaction with carbon dioxide from the gas phase. Therefore, an extra $\mathrm{pH}$ control by buffers or addition of acids was not necessary [7-9].

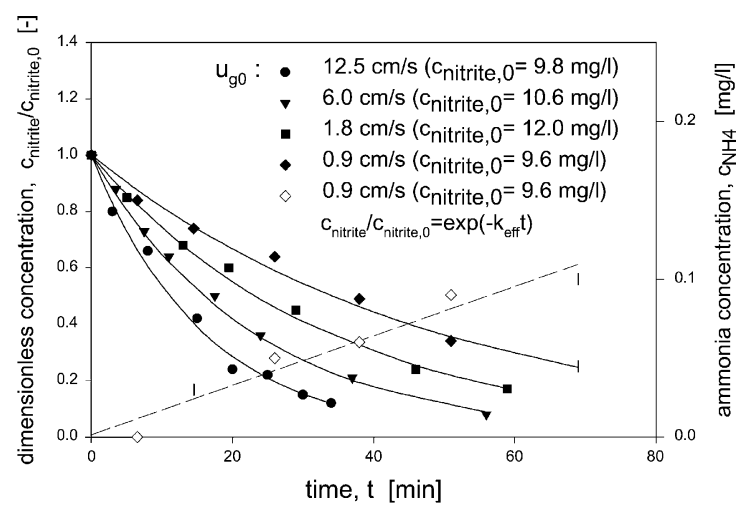

Fig. 2. Nitrite consumption (bold symbols: experiment, line: first-order model), ammonia formation (open symbols) as function of reaction time (over 1\%Pd/AGF catalyst; superficial liquid velocity $u_{10}=1.3 \mathrm{~cm} / \mathrm{s}$ ).

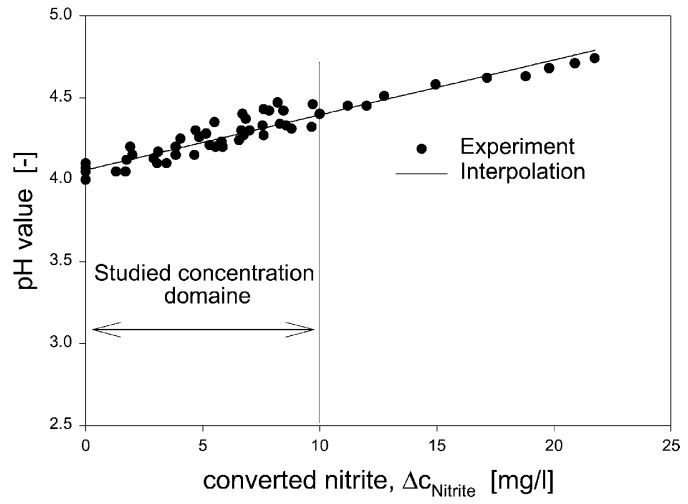

Fig. 3. $\mathrm{pH}$ value as a function of amount of converted nitrite ions for eight experiments.

\subsection{Influence of the hydrodynamics on the over all kinetics}

The superficial gas velocity $u_{\mathrm{g} 0}$ is known to influence strongly the hydrodynamics of staged bubbles columns [19]. Fig. 4 presents the volumetric mass transfer coefficient $k_{\mathrm{L}} a_{\mathrm{G}}[16]$, the frictional pressure drop $\Delta p_{\mathrm{f}}[15]$ and the dimensionless power supply $P$ for the gas compressor as a function of the superficial gas $u_{\mathrm{g} 0}$ velocity. The volumetric gas-liquid mass transfer coefficient $k_{\mathrm{L}} a_{\mathrm{G}}$ was found to increase linearly with the superficial gas velocity $u_{\mathrm{g} 0}$ up to a value of $0.7 \mathrm{~s}^{-1}$. A determination of the $k_{\mathrm{L}} a_{\mathrm{G}}$ value at gas velocities higher than $u_{\mathrm{g} 0}=6 \mathrm{~cm} / \mathrm{s}$ was not possible under the experimental conditions chosen, due to the fast gas-liquid mass transfer. The power supply $P$ increases strongly with the superficial gas velocity. Since the energy costs in a technical scale installation are approximately proportional to the power supply $P$, the superficial gas velocity $u_{\mathrm{g} 0}$ should be optimized to be as low as possible. Therefore, it is indispensable to investigate the global kinetics as a function of the hydrodynamics in the reactor.

The effective reaction rate constant $k_{\text {eff }}$ as a function of the superficial gas velocity $u_{\mathrm{g} 0}$ is presented in Fig. 5 . At low superficial gas velocities $k_{\text {eff }}$ increases strongly with the throughput and tends to a constant value for high velocities.

Three principal mass transfer phenomena may influence the effective reaction rate:

1. Gas-liquid mass transfer of hydrogen. 


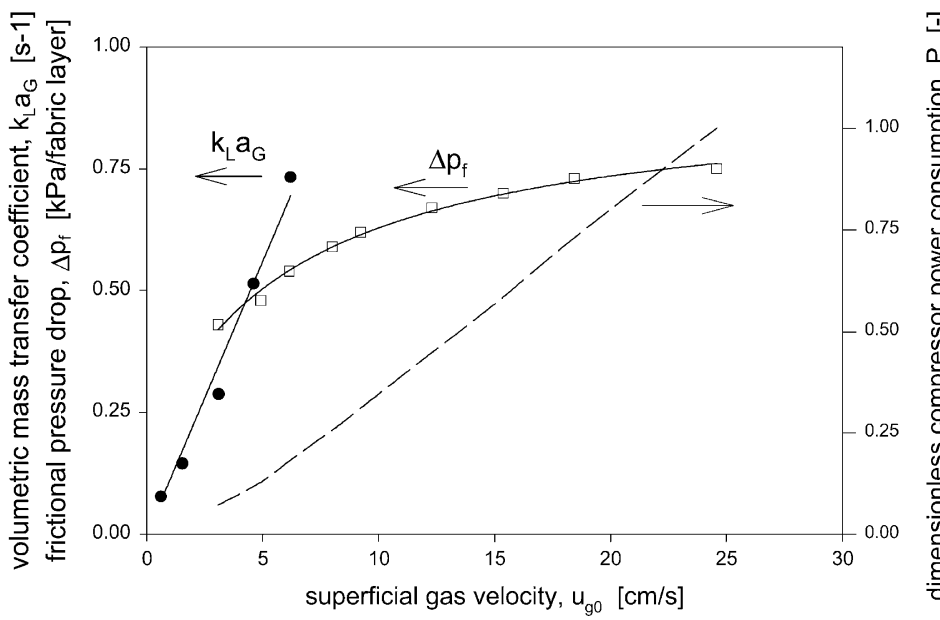

Fig. 4. Volumetric gas-liquid mass transfer coefficient $k_{\mathrm{L}} a_{\mathrm{G}}[16]$, frictional pressure drop $\Delta p_{\mathrm{f}}[15]$ and dimensionless power supply $P$ as a function of the superficial gas velocity $u_{\mathrm{g} 0}$ (superficial liquid velocity $u_{10}=1.3 \mathrm{~cm} / \mathrm{s}$; thread diameter of the fibrous fabrics $D=0.3 \mathrm{~mm}$; distance between the threads $w=0.3 \mathrm{~mm}$ ).

2. Liquid-solid surface mass transfer through the laminar film around the catalyst.

3. Inner mass transfer in the porous catalyst.

The volumetric gas-liquid mass transfer coefficient $k_{\mathrm{L}} a_{\mathrm{G}}$ under the used experimental conditions is higher than $0.08 \mathrm{~s}^{-1}$ and therefore for all experiments about 70 times higher compared to the highest effective reaction constant $k_{\text {eff, } \max }=1.1 \times 10^{-3} \mathrm{~s}^{-1}$ (Fig. 5). Consequently, gas-liquid mass transfer limitations can

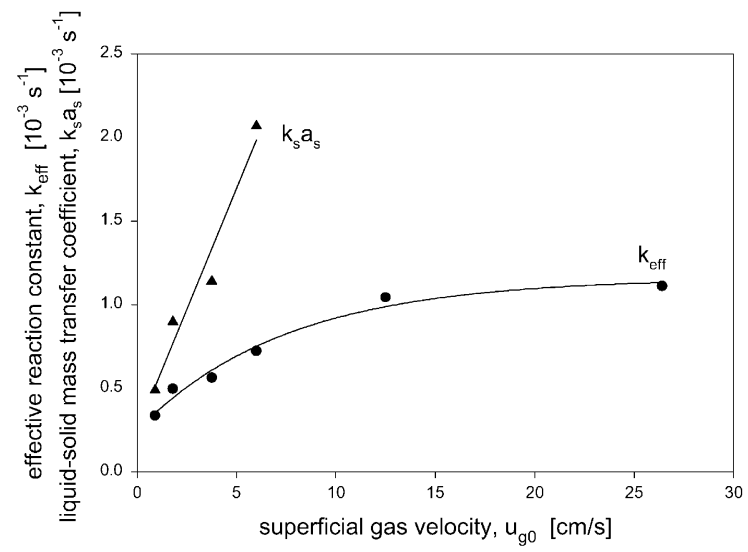

Fig. 5. Effective reaction constant $k_{\text {eff }}$ for the decomposition of nitrite and volumetric liquid-solid mass transfer coefficient $k_{\mathrm{S}} a_{\mathrm{S}}$ as a function of the superficial gas velocity $u_{\mathrm{g} 0}\left(u_{10}=1.3 \mathrm{~cm} / \mathrm{s}\right)$. be excluded. This result is contrary to a recent study of Pintar and Batista [12], which found that the effective nitrate decomposition over egg-shell catalysts was strongly influenced by gas-liquid mass transfer limitations.

The woven fibrous catalyst supports used in this study are considered as macroporous systems. The distances between the filaments were estimated to be in the order of $5 \mu \mathrm{m}$, therefore the inner mass transfer is due to molecular diffusion. To estimate the influence of the inner mass transfer processes on the effective reaction rate, the Weisz modulus was calculated and found to be $4.2 \times 10^{-3}$. The calculation is based on a thread diameter of $0.35 \mathrm{~mm}$, a maximal effective reaction constant $k_{\text {eff, max }}$ of $1.1 \times 10^{-3} \mathrm{~s}^{-1}$ and the effective diffusion coefficient $D_{\text {eff }}$ of $2 \times 10^{-9} \mathrm{~m}^{2} / \mathrm{s}$. The low value for the Weisz modulus indicates that inner mass transport processes do not influence the observed reaction rate [18].

Thus the strong dependence of $k_{\text {eff }}$ with the superficial gas velocity $u_{\mathrm{g} 0}$ may be explained by outer mass transfer limitations. An increase of the gas velocity increases the liquid turbulence, thus decreases the thickness of the laminar film around the catalyst and intensifies the liquid-solid mass transfer [20].

For high gas flow rates the observed reaction rate tends to a constant value and becomes independent from the gas throughput. This value is considered 
as the intrinsic reaction rate, controlled by chemical reaction $\left(k_{\mathrm{eff}} \rightarrow k_{\mathrm{R}}\right.$ for $\left.u_{\mathrm{g} 0}>25 \mathrm{~cm} / \mathrm{s}\right)$. This is confirmed by a comparison of the experimental results with the intrinsic rate constant determined in a batchwise operated stirred tank reactor [13]. The difference between the values, $K_{\mathrm{R} \text {,bubble column }}^{\prime}=$ $k_{\mathrm{R}} V_{\text {liquid }} \mathrm{m}_{\mathrm{pd}}{ }^{-1}=3.81 \mathrm{~min}^{-1} \mathrm{~g}_{\mathrm{pd}}{ }^{-1}$ in this study compared to $K_{\mathrm{R} \text {,stirred tank }}^{\prime}=3.21 \mathrm{~min}^{-1} \mathrm{~g}_{\mathrm{pd}}{ }^{-1}$, may be explained by the difference in the $\mathrm{pH}$ values. Thus the volumetric liquid-solid mass transfer coefficient $k_{\mathrm{S}} a_{\mathrm{S}}$ can be estimated with Eq. (5).

$\frac{1}{k_{\mathrm{S}} a_{\mathrm{S}}\left(u_{\mathrm{g} 0}\right)}=\frac{1}{k_{\mathrm{eff}}\left(u_{\mathrm{g} 0}\right)}-\frac{1}{k_{\mathrm{R}}}$

As shown in Fig. 5 the calculated $k_{\mathrm{S}} a_{\mathrm{S}}$ values increases approximately linearly with the superficial gas velocity. The interfacial area as in this study was approximately $30 \mathrm{~m}^{-1}$ and so comparable low related to random packing with small sizes (e.g. $960 \mathrm{~m}^{-1}$ for Rashig rings with a diameter of $6 \mathrm{~mm}$ [21]). This explains the low $k_{\mathrm{S}} a_{\mathrm{S}}$ values determined in this reactor, which can be increased by decreasing the distance between the catalytic fibrous layers.

The determined ammonia concentrations $c_{\mathrm{NH}_{4}}$ are presented in Fig. 6 as a function of the nitrite conversion $X$ for all experiments. The concentrations increase with increasing nitrite conversion. But even at complete conversion the observed ammonia concentration never exceeds $0.25 \mathrm{mg} / \mathrm{l}$, which corresponds to one-half of the allowable concentration of $0.5 \mathrm{mg} / \mathrm{l}$. In contrary to the rate of nitrite conversion, the ammonia

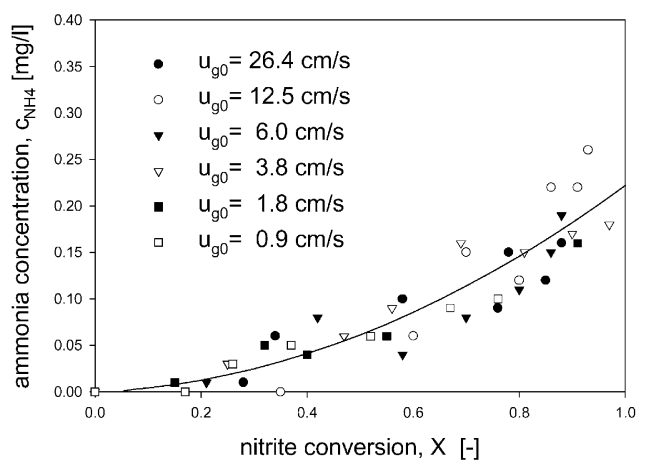

Fig. 6. Ammonia formation as a function of the reaction time for different superficial liquid velocities $\left(u_{10}=1.3 \mathrm{~cm} / \mathrm{s}\right.$, $\left.c_{\text {Nitrite, } 0}=10 \mathrm{mg} / 1\right)$. formation is independent of mass transport phenomena. It can be concluded that the $\mathrm{pH}$ gradient around the catalyst is negligible due to the use of $\mathrm{CO}_{2}$ in the gas phase, even for low gas throughputs.

\section{Conclusions}

- A new reactor concept designed as a bubble column staged with fibrous catalytic layers (1\%Pd/AGF) was tested in a pilot-scale for the reduction of nitrite to nitrogen by hydrogen. Carbon dioxide was used to neutralize the hydroxide ions produced during the hydrogenation of nitrite. Depending on the ions present in the liquid phase a $\mathrm{pH}$ in the range 4-5.5 was observed.

- The effective reaction rate constant $k_{\text {eff }}$ was found to increase strongly at low superficial gas velocities $u_{\mathrm{g} 0}$ with the gas throughput but tends to a constant value for high velocities. It was shown that the reaction rate is independent of the gas-liquid mass transport and that inner mass transport do not influence the observed reaction rate.

- The volumetric liquid-solid mass transfer coefficient $k_{\mathrm{S}} a_{\mathrm{S}}$ was estimated as a function of the superficial gas velocity $u_{\mathrm{g} 0}$.

- The selectivity towards ammonia was found to be independent of the hydrodynamics, even in the regime of strong mass transfer limitations.

\section{Acknowledgements}

The authors would like to thank Mrs. A. Udriot for the preparation of the catalysts. The financial support provided for this work by the Swiss National Foundation, the Swiss Commission for Technology and Innovation and the Max-Buchner Forschungsstiftung is gratefully acknowledged.

\section{References}

[1] A. Kapoor, T. Viraraghavan, J. Environ. Eng. 123 (1997) 371.

[2] S. Hörold, K.D. Vorlop, T. Tacke, M. Sell, Catal. Today 17 (1993) 21.

[3] K.D. Vorlop, U. Prüsse, Catal. Sci. Ser. 1 (1999) 195.

[4] G. Strukul, F. Pinna, M. Marella, L. Meregalli, M. Tomaselli, Catal. Today 27 (1996) 209. 
[5] A.J. Lecloux, Catal. Today 53 (1999) 23.

[6] U. Prüsse, M. Hähnlein, J. Daum, K.D. Vorlop, Catal. Today 55 (2000) 79.

[7] A. Pintar, G. Bercic, J. Levec, AIChE J. 44 (1998) 2280.

[8] A. Pintar, J. Batista, J. Levec, Water Sci. Technol. 37 (1998) 177.

[9] A. Pintar, M. Setinc, J. Levec, J. Catal. 174 (1998) 72.

[10] M. Hähnlein, U. Prüsse, J. Daum, V. Morawsky, M. Kroger, M. Schroder, M. Schnabel, K.D. Vorlop, Preparation of Catalysts VII 118 (1998) 99.

[11] K. Daub, G. Emig, M.J. Chollier, M. Callant, R. Dittmeyer, Chem. Eng. Sci. 54 (1999) 1577.

[12] A. Pintar, J. Batista, Catal. Today 53 (1999) 35.

[13] V. Höller, K. Radevik, I. Yuranov, L. Kiwi-Minsker, A. Renken, Appl. Catal. B 32 (2001) 143.
[14] L. Kiwi-Minsker, I. Yuranov, V. Höller, A. Renken, Chem. Eng. Sci. 55 (1999) 4785.

[15] V. Höller, D. Wegricht, L. Kiwi-Minsker, A. Renken, Catal. Today 60 (2000) 51.

[16] V. Höller, K. Radevik, L. Kiwi-Minsker, A. Renken, Ind. Eng. Chem. Res. 40 (2001) 1575.

[17] Merk, Handbook of Nova 60, Dietikon, Switzerland, 1998.

[18] M. Baerns, H. Hofmann, A. Renken, Chemische Reaktionstechnik, Georg Thieme Verlag, New York, 1992, p. 427.

[19] W.-D. Deckwer, Bubble Column Reactors, Wiley, New York, 1992, p. 533.

[20] O. Levenspiel, Chemical Reaction Engineering, Wiley, New York, 1999, p. 500.

[21] R.H. Perry, D.W. Green (Ed.), Perry's Chemical Engineers' Handbook, 7th Edition, McGraw-Hill, London, 1997, p. 2240. 